\title{
PEMBENTUKAN KARAKTER MANDIRI PADA ANAK USIA DINI MELALUI METODE MONTESSORI DI TK ALMARHAMAH CIMAHI
}

\author{
Cucu Sunarti ${ }^{1}$, Wiwin $S^{2}$, Agus Sumitra ${ }^{3}$ \\ ${ }^{1}$ TK Islam Nuurusyifa \\ ${ }^{2}$ TK Al Marhamah \\ ${ }^{3}$ IKIP Siliwangi Bandung \\ ${ }^{1}$ cucusunarti63@yahoo.com, ${ }^{2}$ wiwinuwie@gmail.com, ${ }^{3}$ agussumitra@ikipsiliwangi.ac.id
}

\begin{abstract}
This journal was to give knowledge for early childhood tutors about learning strategies to improve the emotion social of children abilities. When the learning strategy used by an early childhood tutors was effective, so the achievement level of emotional social intelligence will be maximized and child will grow into a child of character. Character is the key of individual success. It means that someone activity an life wants to succeed, so the absolute requirement must be supported by a strong character capacity. The high character qualities of the community will foster a strong desire to improve the nation quality. In early childhood emotional social development, several assessment reference of early childhood tutor will find it easier to assess and measure the emotional social of children abilities. Learning strategies that are not commonly known by early childhood tutors are learning strategies with Montessori method. Learning with Montessori methode caracter development designed the freedom to think, work and do something.

Key word: Montessori Methode, independence, character.
\end{abstract}

\begin{abstract}
ABSTRAK
Makalah ini untuk memberikan pengetahuan kepada para tutor atau para pendidik PAUD tentang proses belajar pengembangan kemandirian anak didik. Ketika proses pembelajaran yang dipakai seorang pendidik PAUD sudah efektif maka tingkat pembentukkan karakter mandiri anak akan maksimal dan anak akan berkembang dan memiliki karakter. Pembetukan sikap merupakan keberhasilan individu, artinya jika aktivitas dan kehidupan seseorang ingin berhasil maka syarat mutlaknya harus didukung oleh kapasitas karakter yang kuat. Anak usia dini yang berkarakterakan lebih dapat membentuk negara yang maju. . Dalam pembentukan karakter anak usia dini diperlukan beberapa asesmen sebagai acuan penilainannya atau tolak ukur penilaian bagi anak usia dini, sehingga seorang tutor PAUD akan merasa lebih mudah dalam mengevaluasi kemandirian anak didik. Strategi pembelajaran yang belum umum dikenal oleh para pendidik PAUD yaitu strategi pembelajaran dengan metode Montessori. Metode montessori yaitu suatu gaya belajar yang mengharuskan anak belajar secara langsung dan nyata. Karena dengan begitu anak akan mempunyai pengalaman baru dan akan memperoleh ilmu yang baru pula.
\end{abstract}

Kata Kunci: Metode Montessori, Kemandirian, Karakter.

\section{PENDAHULUAN}

Anak usia kisaran antara 4 sampai dengan 6 tahun merupakan usia peniru yang handal yang harus di manfaatkan secara optimal untuk mendapatkan stimulus pembelajaran agar semua aspek perkembangan anak bisa berkembang dengan maksimal. Oleh sebab itu sangat dibutuhkan rangsangan pembelajaran yang sesuai dengan tahapan usia anak. Agar dapat menjadi wadah untuk pengembangan potensi dan bakat yang dimiliki anak. Dan agar 
anak mampu mengatasi problem solving. Di masa depan mereka harus mampu menyatu dengan lingkungan, karena pada hakikatnya anak adalah sosok yang masih harus dibimbing masih membutuhkan sentuhan pengajaran dari orang yang lebih dewasa. Jika cara bersosialisasinya baik sehingga sangat mudah diterima oleh masyarakat, dan sebaliknya jika mereka tidak bisa bersosialisasi dengan baik maka jangan harap bisa beradaptasi dengan teman sebaya yang ada di daerah tempat tinggal. Bersosialisasi disini meliputi cara berkomunikasi yang baik terhadap orang sebaya, kepada yang lebih muda dan kepada yang lebih tua. Anak harus mampu menempatkan diri dan mampu beradaptasi dengan kondisi lingkungan yang beragam. Untuk itu kemandirian anak dibiasakan agar mereka mampu hidup dengan baik di dalam masyarakat luas.

\section{LANDASAN TEORI}

Istilah "karakter kemandirian" awalkata dari mandiri dengan awalan ke- dan akhiran -kan yang membentuk suatu kata sifat. Kebiasaan mandiri selalu berkaitan dengan perkembangan diri sendiri dimana sesorang tidak bergantung kepada orang lain dan percaya kepada dirinya sendiri. Karakter inilah yang harus dibentuk anak sejak usia dini lain dalam menentukkan keputusan dan lepas dari rasa (Fernández Berrocal, n.d.)dari Harvard University dan ("Unidad de Conocimiento - La inteligencia emocional," 2006). ("Unidad de Conocimiento - La inteligencia emocional," 2006)mendefinisikan kecerdasan emosional atau yang sering disebut EQ sebagai: "himpunan bagian dari kecerdasan sosial yang melibatkan kemampuan memantau perasaan sosial yang melibatkan kepekaan terhadap kondisi yang sedang berada didekatnya."

Kecerdasan emosional itu sangat dipengaruhi oleh lingkungan, tidak bersifat menetap, dapat berubah-ubah setiap saat. Oleh karena itu lingkungan memiliki dampak yang besar bagi perkembangan kecerdasankarakter kemandirian anak.

Sifat atau karakter yang mandiri akan memberikan manfaat kehidupan dimasa depan bagi anak, mereka akan terbiasa dengan proses pemcahan masalah dengan sendiri tanpa bantuan orang lain, juga membentuk anak menjadi karakter yang kuat (Goleman, 2000).

(Goleman, 2000) mengungkapkan bahwa aspek pekembangan kecerdasan saja yang harus dikembangkan oleh seorang anak, aspek kognitif, bahasa, moral agama, motorik, sosial emosional pun harus dengan seimbang mendapatkan stimulus agar sama-sama akan berkembang dengan seimbang juga .

(Sri Nurhayati, 2012), kualitas diri merupakan suatu modal untuk bisa hidup berdampingandengan masyarakat banyak. Kemandirian adalah suatu sifat atau karakter yang dapat dilihat dari masyarakat dari suatu daerah yang maju, sehingga semua masyarakatnya produktif dan memajukandaerahnya tersebut." (Goleman, 2000). 
Dalam keseharian kita selalu mendengar kata sifat yang selalu disamaartikan dengan watak, padahal sebenarnya sangat jauh berbeda.

Karakter kemandirian merupakan gabungan dari suatu kebiasaan yang kita lakukan tanpa bantuan dari orang lain. Menurut (Maimunah, 2009), pengertian kemandirian adalah kepercayaan terhadap diri sendiri menyelesaikan suatu hal sampai tuntas tanpa bantuan dari pihak manapun. Karakter kemandirian merupakan modal utama menjadi pribadi yang unggul.

\section{Proses Terbentuknya Karakter}

Watak seseorang pada dasarnya terbentuk melalui proses pembelajaran yang cukup panjang. Watak seorang manusia bukan hanya karena sesuatu yanng menjadi bawaan lahir, tetapi juga akibat dari pengaruh lingkungan dan masyarakat.

Kemandirian terlahir dari sikap percaya padakemampuandiri sendiri. Orangorang yang sangat berpengaruh terhadap pembentukan karakter mandiripada anak yaitu orang tua yang ada di rumah, anggota keluarga lain yang ada di rumah, guru di lingkungan sekoilah danorang-orang disekitar tempat tinggal.

\section{PEMBAHASAN}

\section{A. Pengertian Metode Montessori}

Metode pembelajaran montessori merupakan metode pendidikan yang diperkanalkan oleh seorang penganut agama katholik. Metode montessori adalah suatu strategi yang dibuat oleh Maria Montessori sendiri dari pengalaman yang ia teliti yang ditemukandilapangan pada saat melihat anak autis yang bisa belajar dengan alamai tanpa bantuan orang dewasa (Montessori, n.d.),

Program Montessori didasarkan pada pengalaman pribadi dari Dr. Maria Montessori,bahan,dan metode yang dirancang untuk memenuhi kebutuhan dari childrent improverished di Italia. Metode montessori adalah suatu gaya pembelajaran yang membiarkan anak belajar dengan alami dan dengan sendirinya tanpa campur tangan yang banyak dari gurunya. Guru hanya bertugas memfasilitasi dan menyiapkan media pembelajaran agar pembelajaran berlangsung dan tercapainya tujuan pembelajaran.

Menurut filsafat Dr. Montessori, anakanak belajar dengan baik dalam lingkungan sesuai ukuran, untuk merangsang, serta mempermudah anak untuk menyerap kognitif (pikiran) mereka dalam lingkungan. Pengaturan ruangan diatur seperti yang bisa dijangkau oleh anak dan menggunakan bahan yang tidak berbahaya. Didalam lingkungan tempat tinggal anak dia dapat ,menjadi seseorang yang terbentuk dari apa yang ada dilingkungannya. Misal, seorang anak berminat menjadi seorang yang handal dalam pengelolaan perkebunan,dia tinggal di lingkungan yang mayoritas petani dan lingkungan hijau.

Pembelajaran dengan menggunakan metode montessori lebih memfokuskan 


\begin{tabular}{|c|c|}
\hline USIA & PERKEMBANGAN \\
\hline Lahir - 3 tahun & $\begin{array}{l}\text { > masa } \\
\text { penyerapan total (absorbed } \\
\text { mind), } \\
\text { Perkenalanpengalaman } \\
\text { pancaindera }\end{array}$ \\
\hline $1,5-3$ tahun & >>perkembangan bahasa \\
\hline $1,5-4$ tahun & $\begin{array}{l}\text { > perkembangan dan } \\
\text { koordinasi antara } \\
\text { mata dan otot-ototnya }\end{array}$ \\
\hline $2-4$ tahun & $\begin{array}{l}\text { >>perhatian pada benda-benda } \\
\text { kecil } \\
\text { >>perkembangan dan } \\
\text { penyempurnaan gerakan- } \\
\text { gerakan }\end{array}$ \\
\hline $2,5-6$ tahun & $\begin{array}{l}\text { >>perhatian yang besar pada } \\
\text { hal-hal yang nyata }\end{array}$ \\
\hline $3-6$ tahun & $\begin{array}{l}\text { > mulai menyadari urutan } \\
\text { waktu dan ruang } \\
\text { >>penyempurnaan } \\
\text { penggunaan panca indera }\end{array}$ \\
\hline $3,5-4,5$ tahun & $\begin{array}{l}\text { >>peka terhadap pengaruh } \\
\text { orang dewasa } \\
\text { >>mulai mencoret-coret }\end{array}$ \\
\hline $4-4,5$ tahun & $\begin{array}{l}\text { >>indera peraba mulai } \\
\text { berkembang }\end{array}$ \\
\hline $4,5-5,5$ tahun & $\begin{array}{l}\text { >>Mulai tumbuh minat } \\
\text { membaca }\end{array}$ \\
\hline \multicolumn{2}{|c|}{$\begin{array}{l}\text { pada kegiatan anak yang nyata,jadi } \\
\text { selalu saja ada hasil karya yang anak } \\
\text { buatdenganide dan gagasan dirinya }\end{array}$} \\
\hline
\end{tabular}

Maria Montessori sering menangani anak-anak yang mengalami hambatan belajar seperti halnya anak cacat, autis dan anak-anak korban peperangan jaman dahulu. MariaMontessori menjadi terbiasa menangani anak-anak yang berkebutuhan khusus sehinga beliau mampu dengan handal mengatasi permasalahan perkambangan kecerdasan anak di sekitarnya.Adapun Montessori memberikan bantuan periode sensitif atau masa peka dalam sembilan tahapan sebagai berikut:

Dasar pendidikan metode pembelajaran montessori menekankan pada tiga hal, yaitu:

1) Pendidikan sendiri (pedosentris)

Menurut montessori, anak-anak memiliki kemampuan alamiah untuk berkembang sendiri. Anak punya hasrat alami untuk belajar dan bekerja, bersamaan dengan keinginan anak yang kuat untuk mendapat kesenangan. Anak juga memiliki keinginan untuk mandiri. Dalam hal ini, keinginan untuk mandiri tidak muncul atas perintah dari orang dewasa melainkan keinginan tersebut muncul dalam diri anak itu sendiri. Dorongan alamiah akan terpenuhi dengan memfasilitasi anak dengan aktifitas-aktifitas yang penuh kesibukan. Namun dalam kegiatan tersebut anak harus berlatih sendiri tanpa dibantu.

2) Masa peka

Masa peka adalah masa yang sangat penting dalam perkembangan seorang anak. Ketika masa peka datang, maka anak harus segera difasilitasi dengan alat-alat permainan yang mendukung aktualisasi potensi yang dimiliki. Guru memiliki kewajiban untuk mengobservasi munculnya masa peka dalam diri anak agar dapat memberikan 
tindakan yang tepat sesuai dengan kondisi anak.

\section{3) Kebebasan}

Model pembelajaran montessori memberikan kebebasan kepada anak untuk berfikir, berkarya dan menghasilkan sesuatu. Hal ini dikarenakan masa peka tidak dapat diketahui kapan kepastian kemunculannya. Kebebasan ini bertujuan agar anak dapat mengaktualkan potensi anak sebebasbebasnya. Model pembelajaran montessori memfokuskan pada pengembangan aspek motorik, sensorik dan bahasa. Penekanan utamanya ditempatkan melalui pengembangan alat-alat indera. Model pembelajaran montessori membebaskan anak untuk bergerak, menyentuh, memanipulasi dan bereksplorasi secara bebas. Langkah pembelajaran dalam model pembelajaran montessori terdiri dari tiga langkah yaitu 1) langkah menunjukkan, 2) langkah mengenal, dan 3) langkah mengingat. Contoh langkah menunjukkan : seraya memperlihatkan kertas berwarna merah, guru mengatakan, "ini merah!" begitu juga warna yang lainnya, langkah mengenal: guru mengacaukan kertaskertas berwarna dan berkata kepada anak"Ambillah merah!", langkah mengingat: dari kertas-kertas berwarna yang telah dikacaukan , guru mengambil sehelai kertas dan bertanya, "ini warna ap?"

\section{B. Prinsip-PrinsipMetode Pembelajaran Montessori}

Metode Montessori yaitu suatu strategi belajar agar anak lebih mengalami aktivitas secara nyata dan langsung. Dengan campur tangan guru yang hanya bertugas mengamati sebagai fasilitator. Montessori yaitu suatu strategi yang digunakan guru untuk menstimulus kecerdasan anak secara alami. Model pembelajaran montessori mempersiapkan anak-anak untuk memahami lingkungan sekitar dengan baik. Lima prinsip dasar yang mewakili pendidik. Montessori yang diterapkan dalam berbagai jenis program antara lain:

\section{a. Menghormati Anak}

Menghormati anak merupakan landasan utama, dimana seorang guru menghormati segala sesuatu yang diinginkan anak. Model pembelajaran montessori menekankan pada rasa saling menghormati antara guru dengan murid dan murid dengan guru. Guru membantu anak untuk membentuk pribadi yang mandiri, taat, berperilaku baik, disiplin, serta bertanggung jawab terhadap diri sendiri dan lingkungan sekitar. Peran guru dalam proses pembelajaran montessori adalah sebagai model yang dapat dicontoh ataupun ditiru segala sesuatunya oleh anak. Guru akan menunjukkan rasa hormat kepada anak ketika guru membantu anak dalam melakukan kegiatan. Prinsip awal ini dapat membentuk anak untuk menjadi pribadi yang mampu mengembangkan diri, ketarampilan dan kemampuan dalam pembelajaran yang efektif.

b. Menyerap Pikiran Anak 
Montessori percaya bahwa anak-anak mampu mendidik diri mereka sendiri. Orang dewasa memperoleh pengetahuan dengan menggunakan pemikirannya, namun anak-anak membangun pengetahuannya melalui pengalaman yang diperoleh secara langsung. Konsep pemikiran Montessori dalam menyerap pemikiran anak yaitu agar seorang guru mampu memahami bahwa anak-anak belajar dari lingkungan. Anak-anak belajar bergantung pada guru, pengalaman dan lingkungan anak.

\section{c. Periode sensitif}

Periode sensitif merupakan kondisi ketika anak-anak lebih rentan terhadap perilaku tertentu dan dapat belajar keterampilan khusus lebih mudah. Periode sensitif mengacu pada sensibilitas khusus yang mengakuisisi dalam keadaan infantil. Semua anak mengalami periode sensitif yang sama (misalnya periode sensitifuntuk menulis), urutan dan waktu berbeda untuk setiap anak. Salah satu peran guru adalah dengan menggunakan observasi untuk mendeteksi tingkat sensitivitas dan memberikan pengaturan untuk pemenuhan optimal.

\section{d. Lingkungan yang Siap}

Anak-anak belajar melakukan sesuatu dengan baik melalui lingkungan. Anakanak dapat melakukan hal-hal untuk diri mereka sendiri. Lingkungan siap menjadi bahan pembelajaran dan pengalaman yang tersedia untuk anakanak dalam format yang teratur. Ruang
Kelas Montessori dijelaskan dengab apa yang pendidik anjurkan ketika mereka berbicara tentang pendidikan yang berpusat pada anak dan pembelajaran aktif. Kebebasan adalah karakteristik penting dari lingkungan siap. Sejak anak-anak dalam lingkungan bebas untuk mengeksplorasi bahan yang mereka pilih sendiri, mereka akan menyerap apa yang mereka temukan di sana.

\section{e. Autoeducation (Jatidiri pendidikan)}

Montessori menanamkan konsep bahwa anak-anak mampu mendidik diri mereka sendiri autoeducation (Juga dikenal sebagai diri-pendidikan). Anakanak secara aktif terlibat dalam lingkungan yang siap dan memberi kebebasan harfiah mendidik diri. Guru dalam metode montessori mempersiapkan ruang kelas agar anak mampu mendidik diri mereka sendiri

\section{Implementasi Metode Pembelajaran Montessori di Indonesia}

Penerapan atau implementasi metode Montessori di Indonesia didasarkan pada tiga area dasar keterlibatan anak yaitu :

1. Pendidikan praktis atau gerak motorik meliputi :

a. Lingkungan yang siap menekankan aktivitas dasar sehari-hari. Misal: berjalan dengan tertib, membawa benda seperti baki \& kursi, dlsb.

b. Bingkai berpakaian. Misal: mengancingkan, membuka \& menutup 
resleting, mengikat, menekuk, \& menali. (Lee Gutex, 2013)

c. Aktivitas berbasis air. Misal: menggosok, mencuci, \& menuang. (Sarana pengembangan koordinasi)

d. Latihan kehidupan praktis. Misal: mengelap cermin, sepatu, daun tanaman, meyapu lantai, membersihkan furnitur, \& mengupas sayur.

2. Materi sensorik untuk pelatihan indera meliputi :

a. Melatih indera agar fokus pada beberapa kualitas tertentu yg terlihat seperti Membedakan banyak rangsangan yg diterima. Membuat anak lebih mengenali kapasitas tubuh untuk menerima, menafsirkan, \& menggunakan rangsangan.

b. Membantu mempertajam kekuatan anak untuk mengamati \& membedakan secara visual, Ketrampilan ini berfungsi sebagai dasar bagi kesiapan membaca awal anak.

c. Meningkatkan kemampuan anak untuk berpikir sebagai proses yang bergantung pada kemampuan membedakan, mengklasifikasikan \& mengatur.

3. Materi akademik untuk pengajaran menulis, membaca, \& matematika.

a. Disajikan secara berurutan yg mendukung menulis sebagai basis pembelajaran membaca.

b. Montessori yakin bahwa Anak siap menulis pada usia 4 th,Menulis \& membaca pada usia $4 \& 5$ tahun

\section{Kegiatan pembelajaran metode Montessori di TK Al Marhamah}

Pembelajaran di TK Al Marhamah menggunakan Metode Montessori, seperti di bawah ini akan di jelaskan hasil observasi kegiatan pembelajaran di TK Al Marhamah, diantaranya sebagai berikut:

1. Kegiatan awal melakukan jurnal pagi seperti mengisi absen kelas, anak menulis nama sendiri. Guru hanya membantu menfasilitasi perlengkapan yang akan dipakai oleh anak.

2. Setelah itu anak masuk ke kelas dengan rapi dipandu oleh guru disiapkan untuk solat dhuha sebelum berkegiatan, di Circle Time anak-anak melakukan tepuk semangat, menyebut nama hari, menghitung jumlah teman yang hadir, dan berdoa. Setelah selesai berdoa, anak-anak mengaji bersama guru setelah itu anak-anak diingatkan kembali kegiatan yang dilakukan, dengan berbagi cerita tentang pengalaman saat hari sebelumnya, dan bercakap cakap-cakap tentang ciptaan tuhan. Setelah itu kegiatan inti, dalam kegiatan ini peneliti mengamati bahwa di TK Al Marhamah menggunakan metode Montessori seperti:

a. Menghargai anak, disini anak akan melakukan kegiatan yang dipilih, seperti contohnya pada gambar diatas anak ada yang menyusun balok dan ada pula yang memasang puzzle, peran guru disini hanya mengawasi dan mengarahkan anak, anak berkreasi sesuai imajinasi mereka. 
b. Pengembangan sensori motorik anak, sensorik motorik halus pada anak yang ada di TK Al Marhamah. Seperti pada kelompok A memakai baju sendiri dalam kegiatan bermain peran.

c. Belajar sendiri, Anak bebas memilih media dalam pembelajarannya, peran guru disini hanya mendampingi siswa belajar. Ini membentuk kemandirian siswa sejak dini. Dalam belajar sendiri peneliti melakukan observasi partisipan dengan mengikuti langsung pembelajaran di dalam kelas yang ada di TK Al Marhamah.

d. Anak diarahkan secara menyenangkan baik secara individu ataupun dalam kelompok kecil dalam kegiatan pembentukan karakter yang mandiri, anak memakaisepatu sendiri,menyimpan tas sendiri dan makan sendiri. Dan anak perempuan (Naura) menyusun puzzle hingga membentuk gambar yang sempurna.

e. Pengalaman pada anak memberikan ingatan yang penting pada anak. Dengan adanya pengalaman memberikan anak pengetahuan baru baik itu pengalaman yang menyenangkan maupun menyedihkan. Di TK Al Marhamah anak-anak di berikan berbagai pengalaman di kehidupan nyata. Tujuannya agar anak bisa mengahadapi situasi di lingkungan yang nyata. Seperti pada gambar anak memberi makan kelinci.

f. Practical life, Dalam kegiatan di atas penerapan metode Montessori tentang kemandirrian anak ditugaskan untuk membereskan kembali peralatan makan dan diharapkan memcuci tangan sendiri. Setelah itu anak-anak bertugas membereskan kemabali perlengkapan yang sudah dia pakai. Setelah itu penutup, sebelum sekolah selesai anak di biasakan untuk duduk rapi dan berdoa, lalu anak-anak berbaris dan siap pulang.

\section{HASIL PEMBAHASAN}

Ada beberapa kegiatan pembelajaran yang menjadi tolak ukur penilaian pada perkembangan kecerdasan sosial emosional anak di TK AL Marhamah yang kami catat dan pantau secara nyata dan objektif. Kegiatannya yaitu:

1. Anak terbiasa menyimpan tas dan sepatu ke tempat yang telah guru sediakan (kemandirian):

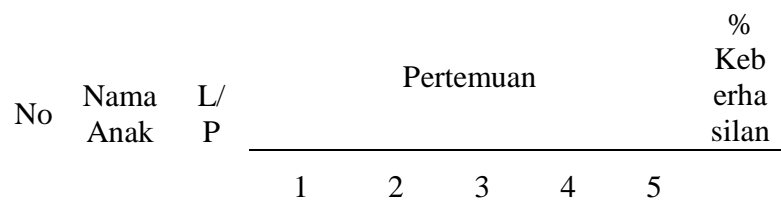

\begin{tabular}{cccccccc}
\hline 1 & $\mathrm{Ar}$ & $\mathrm{L}$ & $\mathrm{BB}$ & $\mathrm{BB}$ & $\mathrm{MB}$ & $\mathrm{MB}$ & $\mathrm{BSH}$ \\
\hline 2 & $\mathrm{At}$ & $\mathrm{L}$ & $\mathrm{BB}$ & $\mathrm{MB}$ & $\mathrm{MB}$ & $\mathrm{MB}$ & $\mathrm{BSH}$ \\
\hline 3 & $\mathrm{An}$ & $\mathrm{L}$ & $\mathrm{BB}$ & $\mathrm{BB}$ & $\mathrm{MB}$ & $\mathrm{MB}$ & $\mathrm{BSH}$ \\
\hline 4 & $\mathrm{Eka}$ & $\mathrm{L}$ & $\mathrm{BB}$ & $\mathrm{MB}$ & $\mathrm{MB}$ & $\mathrm{MB}$ & $\mathrm{BSH}$ \\
\hline 5 & $\mathrm{Hn}$ & $\mathrm{P}$ & $\mathrm{BB}$ & $\mathrm{BB}$ & $\mathrm{MB}$ & $\mathrm{MB}$ & $\mathrm{MB}$ \\
\hline 6 & $\mathrm{Nn}$ & $\mathrm{P}$ & $\mathrm{MB}$ & $\mathrm{BSH}$ & $\mathrm{BSH}$ & $\mathrm{BSH}$ & $\mathrm{BSH}$ \\
\hline 7 & $\mathrm{Rs}$ & $\mathrm{P}$ & $\mathrm{BB}$ & $\mathrm{MB}$ & $\mathrm{MB}$ & $\mathrm{MB}$ & $\mathrm{BSH}$ \\
\hline 8 & $\mathrm{Ry}$ & $\mathrm{L}$ & $\mathrm{BB}$ & $\mathrm{MB}$ & $\mathrm{MB}$ & $\mathrm{MB}$ & $\mathrm{BSH}$ \\
\hline 9 & $\mathrm{Sk}$ & $\mathrm{P}$ & $\mathrm{BB}$ & $\mathrm{BB}$ & $\mathrm{MB}$ & $\mathrm{MB}$ & $\mathrm{BSH}$ \\
\hline 10 & $\mathrm{Sq}$ & $\mathrm{P}$ & $\mathrm{MB}$ & $\mathrm{MB}$ & $\mathrm{BSH}$ & $\mathrm{BSH}$ & $\mathrm{BSH}$ \\
\hline$\%$ & Pencapaian & $20 \%$ & $40 \%$ & $45 \%$ & $65 \%$ & $80 \%$
\end{tabular}

Catatan:

BB : Belum Berkembang

MB : Mulai Berkembang

BSH : Berkembang Sesuai Harapan

BSB : Berkembang Sangat Baik

2. Anak mampu menunggu giliran (antri) tertib saat mengaji iqro (disiplin):

\begin{tabular}{|c|c|c|c|c|c|c|c|c|}
\hline \multirow{2}{*}{ No } & \multirow{6}{*}{$\begin{array}{c}\text { Nama } \\
\text { Anak }\end{array}$} & \multicolumn{6}{|c|}{ Pertemuan } & $\begin{array}{c}\% \\
\text { Keberh } \\
\text { asilan }\end{array}$ \\
\cline { 4 - 9 } & & P & 1 & 2 & 3 & 4 & 5 & $90 \%$ \\
\hline
\end{tabular}




\begin{tabular}{|c|c|c|c|c|c|c|c|c|}
\hline \multirow[t]{2}{*}{ No } & \multirow[t]{2}{*}{$\begin{array}{c}\mathrm{Nam} \\
\mathrm{a} \\
\text { Anak }\end{array}$} & \multirow[t]{2}{*}{$\begin{array}{l}\mathrm{L} / \\
\mathrm{P}\end{array}$} & & & & & & $\begin{array}{c}\% \\
\text { Keber } \\
\text { hasila } \\
n\end{array}$ \\
\hline & & & 1 & 2 & 3 & 4 & 5 & \multirow{11}{*}{$95 \%$} \\
\hline 1 & $\mathrm{Ar}$ & $\mathrm{L}$ & $\mathrm{BB}$ & $\mathrm{BB}$ & MB & MB & $\mathrm{BSH}$ & \\
\hline 2 & At & $\mathrm{L}$ & $\mathrm{BB}$ & MB & $\mathrm{BSH}$ & $\mathrm{BSH}$ & $\mathrm{BSH}$ & \\
\hline 3 & An & $\mathrm{L}$ & $\mathrm{BB}$ & $\mathrm{BB}$ & MB & MB & $\mathrm{BSH}$ & \\
\hline 4 & Eka & $\mathrm{L}$ & $\mathrm{BB}$ & MB & $\mathrm{MB}$ & MB & $\mathrm{BSH}$ & \\
\hline 5 & $\mathrm{Hn}$ & $\mathrm{P}$ & $\mathrm{BB}$ & $\mathrm{BB}$ & $\mathrm{BSH}$ & $\mathrm{BSH}$ & $\mathrm{BSH}$ & \\
\hline 6 & $\mathrm{Nn}$ & $\mathrm{P}$ & MB & $\mathrm{BSH}$ & $\mathrm{BSH}$ & $\mathrm{BSH}$ & $\mathrm{BSH}$ & \\
\hline 7 & Rs & $\mathrm{P}$ & $\mathrm{BB}$ & MB & MB & MB & $\mathrm{BSH}$ & \\
\hline 8 & Ry & $\mathrm{L}$ & $\mathrm{BB}$ & MB & MB & MB & $\mathrm{BSH}$ & \\
\hline 9 & Sk & $\mathrm{P}$ & $\mathrm{BB}$ & $\mathrm{BB}$ & MB & MB & $\mathrm{BSH}$ & \\
\hline \begin{tabular}{l|l}
10 \\
\end{tabular} & $\mathrm{Sq}$ & $\mathrm{P}$ & $\mathrm{MB}$ & MB & $\mathrm{BSH}$ & $\mathrm{BSH}$ & $\mathrm{BSH}$ & \\
\hline \multicolumn{3}{|c|}{$\%$ Pencapaian } & $20 \%$ & $40 \%$ & $50 \%$ & $70 \%$ & $85 \%$ & \\
\hline 1 & $\mathrm{Ar}$ & $\mathrm{L}$ & $\mathrm{BB}$ & $\mathrm{BB}$ & $\mathrm{MB}$ & $\mathrm{MB}$ & BSH & \\
\hline 2 & At & $\mathrm{L}$ & BB & MB & MB & MB & BSH & \\
\hline 3 & $\mathrm{An}$ & $\mathrm{L}$ & $\mathrm{BB}$ & $\mathrm{BB}$ & MB & MB & $\mathrm{BSH}$ & \\
\hline 4 & $\begin{array}{l}\text { Ek } \\
\mathrm{a}\end{array}$ & $\mathrm{L}$ & BB & MB & MB & MB & $\mathrm{BSH}$ & \\
\hline 5 & $\mathrm{Hn}$ & $\mathrm{P}$ & BB & BB & BSH & MB & MB & \\
\hline 6 & $\mathrm{Nn}$ & $\mathrm{P}$ & $\mathrm{BB}$ & $\mathrm{BSH}$ & BSH & BSH & $\mathrm{BSH}$ & \\
\hline 7 & Rs & $\mathrm{P}$ & $\mathrm{BB}$ & MB & MB & MB & BSH & \\
\hline
\end{tabular}

\begin{tabular}{|c|c|c|c|c|c|c|c|c|}
\hline \multirow{2}{*}{ No } & \multirow{2}{*}{$\begin{array}{c}\text { Nam } \\
\text { a } \\
\text { Anak }\end{array}$} & \multirow{2}{*}{$\begin{array}{l}\mathrm{L} / \\
\mathrm{P}\end{array}$} & \multicolumn{5}{|c|}{ Pertemuan } & $\begin{array}{c}\% \\
\text { Keb } \\
\text { erha }\end{array}$ \\
\hline & & & 1 & 2 & 3 & 4 & 5 & \multirow{11}{*}{$\begin{array}{c}100 \\
\%\end{array}$} \\
\hline 1 & $\mathrm{Ar}$ & $\mathrm{L}$ & $\mathrm{BB}$ & $\mathrm{BB}$ & MB & MB & BSH & \\
\hline 2 & At & $\mathrm{L}$ & $\mathrm{BB}$ & $\mathrm{MB}$ & MB & $\mathrm{MB}$ & $\mathrm{BSH}$ & \\
\hline 3 & An & $\mathrm{L}$ & BB & BB & MB & MB & BSH & \\
\hline 4 & Eka & $\mathrm{L}$ & $\mathrm{BB}$ & MB & MB & MB & $\mathrm{BSH}$ & \\
\hline 5 & $\mathrm{Hn}$ & $\mathrm{P}$ & $\mathrm{BB}$ & $\mathrm{BB}$ & $\mathrm{MB}$ & MB & $\mathrm{BSH}$ & \\
\hline 6 & $\mathrm{Nn}$ & $\mathrm{P}$ & $\mathrm{MB}$ & $\mathrm{BSH}$ & BSH & $\mathrm{BSH}$ & BSH & \\
\hline 7 & Rs & $\mathrm{P}$ & MB & MB & MB & $\mathrm{MB}$ & BSH & \\
\hline 8 & Ry & $\mathrm{L}$ & MB & MB & MB & MB & BSH & \\
\hline 9 & $\mathrm{Sk}$ & $\mathrm{P}$ & $\mathrm{BB}$ & $\mathrm{BB}$ & MB & $\mathrm{MB}$ & $\mathrm{BSH}$ & \\
\hline 10 & $\mathrm{Sq}$ & $\mathrm{P}$ & $\mathrm{MB}$ & $\mathrm{MB}$ & $\mathrm{BSH}$ & $\mathrm{BSH}$ & $\mathrm{BSH}$ & \\
\hline \multicolumn{3}{|c|}{$\%$ Pencapaian } & $30 \%$ & $640 \%$ & $45 \%$ & $65 \%$ & $80 \%$ & \\
\hline 8 & Ry & $\mathrm{L}$ & $\mathrm{BB}$ & $\mathrm{MB}$ & MB & MB & BSH & \\
\hline 9 & Sk & $\mathrm{P}$ & $\mathrm{BB}$ & $\mathrm{BB}$ & $\mathrm{MB}$ & $\mathrm{MB}$ & $\mathrm{BSH}$ & \\
\hline 10 & $\mathrm{Sq}$ & $\mathrm{P}$ & MB & MB & $\mathrm{BSH}$ & BSH & BSH & \\
\hline \multicolumn{3}{|c|}{$\begin{array}{c}\% \\
\text { encapa }\end{array}$} & $15 \%$ & $40 \%$ & $45 \%$ & $65 \%$ & $80 \%$ & \\
\hline
\end{tabular}

Catatan:

BB : Belum Berkembang

MB : Mulai Berkembang

BSH : Berkembang Sesuai Harapan

BSB : Berkembang Sangat Baik
3. Anak berani mencuci tangan sendiri kekamar mandi tanpa dibantu ibu guru (kemandirian):

Catatan:

BB : Belum Berkembang

MB : Mulai Berkembang

BSH : Berkembang Sesuai Harapan

BSB : Berkembang Sangat Baik

4. Anak mampu berinteraksi dan berteman baik dengan teman sebaya (sosialisasi):

Catatan:

BB : Belum Berkembang

MB : Mulai Berkembang

BSH : Berkembang Sesuai Harapan

BSB : Berkembang Sangat Baik

5. Anak mampu merapikan kembali mainan yang sudah digunakan (pembiasaan):

\begin{tabular}{|c|c|c|c|c|c|c|c|}
\hline \multirow{2}{*}{$\begin{array}{l}\text { Nama } \\
\text { Anak }\end{array}$} & \multirow{2}{*}{$\begin{array}{l}\mathbf{L} / \\
\mathbf{P}\end{array}$} & \multicolumn{5}{|c|}{ Pertemuan } & \multirow{2}{*}{$\begin{array}{c}\% \\
\text { Keberh } \\
\text { asilan }\end{array}$} \\
\hline & & 1 & 2 & 3 & 4 & 5 & \\
\hline $\mathrm{Ar}$ & $\mathrm{L}$ & BB & BB & MB & $\mathrm{MB}$ & BSH & \multirow{10}{*}{$100 \%$} \\
\hline At & $\mathrm{L}$ & $\mathrm{BB}$ & MB & MB & MB & BSH & \\
\hline An & $\mathrm{L}$ & $\mathrm{BB}$ & BB & MB & MB & BSH & \\
\hline Eka & $\mathrm{L}$ & $\mathrm{BB}$ & MB & MB & MB & BSH & \\
\hline $\mathrm{Hn}$ & $\mathrm{P}$ & $\mathrm{BB}$ & BB & MB & MB & BSH & \\
\hline $\mathrm{Nn}$ & $\mathrm{P}$ & MB & $\mathrm{BSH}$ & BSH & BSH & BSH & \\
\hline Rs & $\mathrm{P}$ & MB & MB & MB & MB & $\mathrm{BSH}$ & \\
\hline Ry & $\mathrm{L}$ & MB & MB & MB & MB & BSH & \\
\hline Sk & $\mathrm{P}$ & MB & MB & MB & MB & BSH & \\
\hline $\mathrm{Sq}$ & $\mathrm{P}$ & MB & MB & BSH & BSH & $\mathrm{BSH}$ & \\
\hline & & $35 \%$ & $40 \%$ & $45 \%$ & $65 \%$ & $95 \%$ & \\
\hline
\end{tabular}

Catatan:

BB : Belum Berkembang

MB : Mulai Berkembang

BSH : Berkembang Sesuai Harapan

BSB : Berkembang Sangat Baik

Berdasarkan observasi yang telah kami lakukan pada anak-anak kelompok A di TK Al Marhamah, mengenai penerapan metode Montessori berbasis penguatan 


\section{JURNAL CERIA}

ISSN : 2614-6347 (Print) 2614-4107 (Online)

Vol.1」No.2 $\mid$ Maret 2018

karakter, maka dapat kami simpulkan bahwa penerapan metode montessori tersebut secara umum dinyatakan berhasil (rentang pencapaian 90\% $100 \%)$.

\section{KESIMPULAN}

Melatih kecerdasan sosial emosional anak usia dini dengan cara menerapkan pembelajaran dengan metode Montessori berbasis penguatan karakter di dalam kelas adalah cara yang efektif, karena anak akan cenderung mengandalkan kemampuannya dalam berkomunikasi, berteman, dan bergaul dengan teman sebaya di lingkungannya secara alami.

Pembelajaran yang statis atau monoton dan baku akan melatih kemampuan anak dengan cara memberikan tugas individu sehingga akan cenderung membuat anak merasa tidak bebas, kemandirian akan kurang, anak tidak ekspresif, anak kurang bisa mengeksplorasi potensi dan bakat yang ada dalam dirinya, terbentuknya karakter yang lemah, akan merasa tidak penting untuk berteman yang baik, bahkan tidak mengetahui cara bagaimana memulai pertemanan dengan teman sebaya, tidak mengetahui cara meminjam, tidak mengetahui cara berterimakasih dan kemampuan bersosialisasinya akan tumpul. Sehingga itu hanya akan mencetak anak-anak yang gagal alias anak-anak yang berkarakter tipe pekerja karena mengurung tingkat kreativitas anak dalam berkarya di masa depan.

\section{DAFTAR PUSTAKA}

Fernández Berrocal, P. (n.d.). Emotional Intelligence and emotional education from Mayer and Salovey's model. Retrieved from

http://emotional.intelligence.uma.e s/documentos/pdf61modelo_de_m ayer_salovey.pdf

Goleman, D. (2000). Kecerdasan Emosional. GramediaPustaka Utama. Retrieved from https://books.google.co.id/books?h l=id\&lr=\&id=fYLEGIKrtNYC\&oi $=$ fnd $\& p g=$ PA $181 \& d q=$ Kecerdasan +Emosional\&ots=ASol39iAYU\&s ig=hjli5kIz6QsqF1InnlrG5Zn7A1g \&redir_esc $=\mathrm{y} \# \mathrm{v}=$ onepage $\& \mathrm{q}=\mathrm{Kec}$ erdasan Emosional $\& \mathrm{f}=$ false

Lee Gutex. (2013). Metode Montessori Panduan Guru dan Orang Tua Didik PAUD. Yogyakarta: Pustaka Pelajar. 


\section{JURNAL CERIA}

ISSN : 2614-6347 (Print) 2614-4107 (Online)

Maimunah, H. (2009). Pendidikan Anak

Usia Dini. Yogyakarta: Diva

Press.

Montessori, M. (n.d.). The Montessori method. Retrieved from

https://books.google.co.id/books?h $1=\mathrm{id} \& \mathrm{lr}=\& \mathrm{id}=\mathrm{LTL} w A Q A A Q B A J$

$\& o i=$ fnd \&pg=PP1 \&dq=montessori \&ots $=$ PtTGG-

gz4V\&sig=4brePkV7abOihn5lRzr

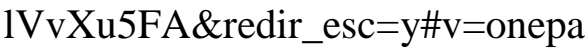
ge\&q=montessori $\& \mathrm{f}=$ false

Sri Nurhayati. (2012). Menimbang

Model Pendidikan Anak Usia Dini. Cimahi: Trim Komunikata.

Unidad de Conocimiento - La inteligencia emocional. (2006).

Retrieved from

https://factorhuma.org/attachments

_secure/article/8301/IE_cast.pdf 